\title{
Verbond en sakrament/doop in die intertestamentêre literatuur
}

\section{GMM PELSER}

Wat bogenoemde onderwerp betref, is daar slegs twee gebruike wat tot op sekere hoogte ons aandag verdien, en dit is die proselietedoop by die Jodedom en die rituele bad by geleentheid van die opname van ' $n$ nuwe lid in die Koemraangemeenskap. Albei hierdie gebruike het wel gepaard gegaan met die opname van ' $n$ persoon in ' $n$ verbondsgemeenskap, maar die vraag of ons hiervan as sakrament of doop in die gebruiklike sin van die woord kan praat, moet voorlopig onbeantwoord bly. Hierop sal ons eers kan antwoord nadat ons ons vergewis het van die betekenis wat hierdie praktyke gehad het in die onderskeie kringe waarin hulle beoefen is.

Dat die besnydenis by die Jodedom in die intertestamentêre en Nuwe-Testamentiese tyd as die uitsluitlike verbondsteken beoefen is en gegeld het, het geen bewysvoering nodig nie. Die gewigtigste Skrifgrond wat hiervoor aangevoer is, is die opdrag aan Abraham in Gen 17. Teologies gesproke was die besnydenis vir die Jode die teken en seël dat hulle deel van die Abrahamsverbond was en daarom aan God behoort het. As teken dat hulle aan die Godsvolk behoort het, is dit dan ook beskou as een van die voorskrifte wat hulle met vreugde moes aanvaar en moes uitvoer. Dit is aan die besnydenis te danke dat Israel die beloofde land as besit ontvang het en dat God die volk se beskermer geword het. Die grootste seën sal die besnydenis egter in die toekoms ten gevolg hê: vanweë die verdienste van die besnydenis sal Israel in die messiaanse tyd verlos word en in die toekomstige wêrreld uit die gehinnom gered word. So belangrik is die besnydenis geag, dat dit gereken is onder een van die belangrikste pligte wat 'n vader teenoor sy seun moes nakom. In die traktaat Qid 29a Bar word dit as die eerste plig genoem vóór byvoorbeeld die onderrig in die Torah. Dit is ook as so belangrik geag dat dit selfs op die sabbatdag gedoen moes word, indien die agste dag na geboorte op 'n sabbatdag sou val (kyk Strack \& Billerbeck V, 1969: 24 vv vir bewysmateriaal). Dit is verder algemene kennis dat die besnydenis ook geword het tot dié teken waarmee die Jode hulleself van alle nie-Jode onderskei het (peritome teenoor akrobustia vgl bv Rom 4:12; Ef 2:11), egter nie heeltemal ten regte nie, aangesien daar ook ander volke was wat die besnydenis beoefen het. 


\section{DIE PROSELIETEDOOP}

\subsection{Ontstaan}

Daar heers nie eenstemmigheid oor die vraag of ' $n$ reinigingsbad reeds vóór die Nuwe-Testamentiese tyd deel uitgemaak het van die handelinge by geleentheid van die opname van 'n proseliet in die Joodse religieuse gemeenskap nie (kyk bv Pusey 1984: $141 \mathrm{v}$ ). Voor die NuweTestamentiese tyd het die verskynsel hom reeds vir geruime tyd voorgedoen dat nie-Jode hulle by die Joodse godsdiens aangesluit het, maar nêrens in die intertestamentêre literatuur word daarvan gewag gemaak dat dit geskied het by wyse van 'n "doop" nie. Alle aanduidings is egter dat die besnydenis uit die staanspoor as opnamerite gegeld het (kyk bv Eks 12:48). Dit sou net ondenkbaar wees dat iemand voluit lid kon word van die Joodse religieuse gemeenskap sonder dat hy besny sou word. Dit is bekend dat daar in die diaspora nie so sterk by nieJode aangedring is op volle oorgang tot die Joodse geloof, wat dan ook besnydenis sou behels nie, vandaar die talle sebomenoi/foboumenoi. Maar ook hier het gegeld dat jy alleen vol-Israeliet kon wees, as jy jou laat besny en onderneem om al die gebooie te onderhou (vgl Kuhn: $731,734)$. Terwyl ons dus kan aanvaar dat die besnydenis van die begin af as opnamerite gegeld het, kan ons dit vanweë 'n gebrek aan gegewens, nie met dieselfde stelligheid met betrekking tot die reinigingsbad (tebilāh) beweer nie.

Die vroegste skriftelike getuienis oor die aangeleentheid dateer uit \pm 200 n.C., sonder dat daarin egter enige aanduiding betreffende die invoering van die reinigingsbad gegee word. In die Mishna traktaat Pes 8:8 word daar naamlik gewag gemaak van 'n meningsverskil wat onderskeidelik tussen die skole van Hillel en Shammai geheers het oor hoe gou na die besnydenis die reinigingsbad deur die proseliet geneem kon word. Laasgenoemde was van mening dat 'n proseliet onmiddellik na sy besnydenis die bad kon neem en dan aan byvoorbeeld die pasga kon deelneem. Eersgenoemde daarenteen het beslis dat dit eers na sewe dae mag gebeur. Hierdie siening is gefundeer met die uitspraak dat iemand wat hom van die voorhuid skei, vergelykbaar is met iemand wat hom van die graf skei. Dit is moeilik om uit te maak wat presies hiermee bedoel is, maar hieruit kan kwalik iets anders afgelei word as dat so iemand vir dieselfde tydperk as onrein beskou is as iemand wat in aanraking met ' $n$ lyk of 'n graf was, naamlik sewe dae (kyk Num 19:16). Eers hierna kon hy dus die bad neem.

Hoewel ons nie in hierdie Mishna traktaat enige aanduiding oor die 
ontstaansdatum van die reinigingsbad het nie, lyk dit tog nie te vergesog om hieruit die afleiding te maak dat dit alreeds vóór die NuweTestamentiese tyd in gebruik moes gewees het nie. Die wyse waarop hier oor die reinigingsbad gepraat word, gee die indruk dat dit toe al 'n erkende en vaste gebruik was. Verskeie geleerdes aanvaar dan ook dat hierdie gebruik inderdaad reeds voor die tyd van die Nuwe Testament ontstaan het (bv Strack \& Billerbeck I 1969: 103; Oepke: 533).

\subsection{Die elemente van en handelinge by die toetredingsaksie}

Hoewel daar ook nie volkome sekerheid bestaan oor die verskillende elemente wat deel uitgemaak het van die toetredingsaksie van die proseliet nie (vgl Sanders 1977: 206), blyk dit dat minstens drie met sekerheid onderskei kan word, naamlik besnydenis, reinigingsbad en die bring van 'n offer deur die proseliet. Aangesien laasgenoemde alleen by die tempel kon geskied, het dit vanselfsprekend ná 70 n.C. verval. As hoe noodsaaklik of gebiedend die offer geag is, is moeilik om te sê. Neem ' $n$ mens egter in aanmerking dat dit alleen by die tempel gebring kon word, dan laat dit jou wonder of dit nie in die diaspora dikwels nagelaat is nie. Dit wil in elk geval lyk asof die besnydenis en die reinigingsbad van ' $n$ bepaalde tyd af gegeld het as die belangrikste elemente.

Is een van die twee nou as belangriker gesien as die ander of is aan albei ewe veel waarde geheg? Ongelukkig het ons ook wat hierdie vraag betref, nie veel gegewens tot ons beskikking nie, hoewel ons hier en daar uit die rabbynse literatuur 'n paar afleidings kan maak. Uit die hierbo genoemde meningsverskil tussen die skole van Hillel en Shammai, kan alreeds die afleiding gemaak word dat laasgenoemde aan die besnydenis die prominenter plek toegeken het en dit so moes verstaan het dat die proseliet daarmee reeds ten volle na die nuwe religieuse gemeenskap toe oorgegaan het. Dit word bevestig deur 'n mededeling p J 8:9a, b en b Schab 135a Bar waaruit blyk dat die skool van Shammai selfs in die geval van 'n proseliet wat reeds voorheen besny was, vereis het dat hy nogtans besny moet word sodat "die bloed van die verbond van hom kon afdrup". Hierteenoor wil dit voorkom of die skool van Hillel weer meer klem op die reinigingsbad gelê het. So vind ons hierdie onderskeie standpunte rondom 90 n.C. ook nog by Eliezer ben Hirkanus aan die een en Jehoshua ben Gananja aan die ander kant $J^{\mathrm{e} b}$ $46^{2}$ Bar). Eersgenoemde wat die Shammai standpunt onderskryf het, was van oordeel dat 'n mens voluit proseliet is, sonder dat jy gedoop 
hoef te wees, solank jy net besny is. Vir laasgenoemde weer het die reinigingsbad jou voluit proseliet gemaak, sonder dat jy besny hoef te wees. Nie een van hierdie standpunte is egter deur die tydgenootlike rabbi's gedeel nie, en dit is duidelik dat teen die einde van die eerste eeu dit die mees algemene opinie was dat besnydenis en reinigingsbad 'n gelykwaardige plek beklee het.

Hoewel die belangrikheid en funksiè van die reinigingsbad by die Rabbyne dus gewissel het afhangende van die kring waarin dit beoefen is, blyk dit tog dat dit in die meeste gevalle as 'n belangrike element by die toetredingsaksie beskou is. Dit is ook te begrype in die lig van die feit dat die nie-Jood tradisioneel as ritueel onrein gegeld het en kwalik tot die Joodse religieuse gemeenskap toegelaat sou word sonder voorafgaande rituele reiniging (kyk o.a. Schürer 1977: 83 v; 285 noot 58 en vgl Hand 10:11 vv, 28).

Wat die ander handeling by die toetredingsaksie betref, is dit vir ons doel belangrik om te let op wat aan die proseliet by hierdie geleentheid voorgehou is $\left(J^{e} b 47^{a}\right.$ Bar). Reeds voor sy besnydenis word die erns van die saak aan hom verduidelik en word hy vertroud gemaak met 'n deel van die ligtere en 'n deel van die gewigtige gebooie en gewys op sowel die straf vir oortreding daarvan as die loon vir die nakoming daarvan. Wanneer hy dan na sy besnydenis die reinigingsbad ('n volledige wassing) neem, word dit gedoen in die teenwoordigheid van twee leerlingrabbi's wat as getuies optree en wat weer aan hom 'n deel van die ligtere en 'n deel van die gewigtige gebooie voorhou. $\mathrm{Na}$ afhandeling van die reinigingsbad, wat deur die proseliet self onderneem is, geld hy dan as ware Israeliet. In die geval van 'n vrou, word sy deur 'n vrou bygestaan, terwyl die leerlingrabbi's buite staan en ook aan haar die gebooie voorhou.

Die klem wat by hierdie geleentheid op die gebooie en die nakoming daarvan gelê is, berus vanselfsprekend daarop dat die gehoorsaming en nakoming van die gebooie as van deurslaggewende belang geag is vir deelname aan die verbond. Hoewel die verbond nie in bogenoemde beskrywing vermeld word nie, moes dit duidelik die veronderstelling gewees het. Dit is soos Sanders dit stel "... accepting the covenant both requires and is evidanced by obeying the commandments. ... Thus the definition of a proper proselyte is that he is a ger tsaddiq, a 'righteous proselyte'; that is, like a righteous (nativeborn) Israelite he obeys the Thorah" (1977: 206). 


\subsection{Wie was betrokke}

Uit die gegewens blyk dat in die geval van 'n gesin die voorgeskrewe handelinge nie alleen ten opsigte van die ouers gegeld het nie, maar ook van die kinders. Met betrekking tot die kinders is verder van die standpunt uitgegaan dat hulle by volwassewording self kon besluit of hulle in die Joodse religieuse gemeenskap wou bly of hulle daarvan wou losmaak. In geval hulle besluit het om hulle daarvan los te maak, is hulle egter nie as afgedwaaldes beskou nie, maar gewoon as buite die gemeenskap soos enige ander nie-Jood $\left(K^{e_{t h}} 11^{a}\right)$. Kinders wat na die toetrede van hulle ouers gebore is, is nie gedoop nie, aangesien hulle as volwaardige Jode beskou is $\left(\mathrm{J}^{\mathrm{e}} \mathrm{b} 78^{\mathrm{a}}\right)$.

\subsection{Die verhouding "doop" en verbond}

Tradisioneel is daar veral deur Nuwe-Testamentici 'n taamlik ongunstige beeld oorgehou van die godsdienstige opvattinge en praktyke van die Jodedom in die Nuwe-Testamentiese tyd. Die beeld wat oorwegend voorgehou is, is die van legalisme en van 'n ingesteldheid waarvolgens redding alleen op verdienste deur die nakoming van gebooie en voorskrifte sou berus. In die laaste paar dekades het 'n aantal geleerdes egter sterk besware gelug teen hierdie beskouing wat deur hulle gesien word as heeltemal te eensydig, nie op alle beskikbare gegewens gegrond nie en 'n karikatuur van die Jodedom. Die eerste bydrae in hierdie verband wat deur baie as 'n keerpunt beskou word, is die werk van Davies (1958). Hy het aangetoon dat daar vir baie van die Pauliniese motiewe wat vroeër as Hellenisties beskou is, parallelle by die Palestynse Jodedom gevind kan word, soos verteenwoordig in die rabbynse literatuur. Na Davies het ook ander geleerdes soortgelyke standpunte gestel. In een van die meer onlangse bydraes oor die aangeleentheid, naamlik dié van Sanders, word die saak soos volg opgesom: "The pattern is this: God has chosen Israel and Israel has accepted the election. In his role as King, God gave Israel commandments which they are to obey as best they can. Obedience is rewarded and disobedience punished. In case of failure to obey, however, man has recourse to divinely ordained means of atonement, in all of which repentance is required. As long as he maintains his desire to stay in the covenant, he has a share in God's covenantal promises, including life in die world to come. The intention and effort to be obedient constitute the condition for remaining in the covenant, but they do not earn it" (1977:180).

Indien hierdie herwaardering van die Joodse religieuse ingesteldheid korrek is, en ons het nie afdoende rede om dit ernstig te bevraagteken nie, dan beteken dit dat ons die verbondsbegrip by die Jodedom 
in die Nuwe-Testamentiese tyd nie eensydig as legalisties mag tipeer nie. Al is dit so dat Torah dikwels as sinoniem met verbond gesien is, moet dit in konteks verstaan word en moet daar nie te maklik veralgemeen word nie. Dat die nakoming van die gebooie in sekere kringe oorbeklemtoon is, kan egter eweneens nie ontken word nie.

Hoewel daar in die rabbynse voorskrifte en menings oor proselietwording nie eksplisiet oor die verbond gereflekteer word nie, was die veronderstelling vanselfsprekend dat die proseliet by hierdie geleentheid in die Joodse verbondsgemeenskap opgeneem is, en daarmee ook opgeneem is in die verbond met al die voorregte en verpligtinge daaraan verbonde. Die eis wat die skool van Shammai met betrekking tot die besnydenis as verbondsteken gestel het, wys duidelik in hierdie rigting. Selfs in gevalle waar die besnydenis miskien nie as ' $n$ absolute vereiste gestel is nie, sou toetrede deur middel van die reinigingsbad nog steeds toetrede tot die verbondsgemeenskap en verbond beteken het. Teen hierdie tyd moes die proseliet ook reeds op hoogte gewees het met wat die verbond behels en impliseer. Dit is egter opvallend dat daar by geleentheid van die reinigingsbad slegs gebooie aan hom voorgehou is en nie ook iets van die verbond as gawe van God nie.

Wat ons egter veral interesseer is die vraag of in die geval van die proseliet alleen die besnydenis of ook die reinigingsbad as verbondsteken gesien is. Uit wat reeds onder 1.1 hierbo opgemerk is in verband met die besnydenis as aanvanklike opnamerite, asmede uit die feit dat die besnydenis in die meeste gevalle van proselietwording sonder twyfel die prominentste rol gespeel het, lyk die afleiding onvermydelik dat hierdie kwalifikasie alleen die besnydenis toekom. Tereg merk Lohse (1960: 972) in hierdie verband op: "Die schwerste Bedingung stellte jedoch die Forderung der Beschneidung dar, da durch sie nicht nur der Anschluss an eine Religionsgemeinschaft, sondern auch der Übertritt zum jüd. Volksverband vollzogen wurde". Dit is immers in ooreenstemming met die tradisionele rol wat die besnydenis by die Jodedom vervul het, veral ook gesien in die lig van die feit dat daar in die rabbynse literatuur na aanleiding van Gen 17:10, na die besnydenis gewoon deur middel van die term $b^{e}$ rit verwys is.

Daar sal natuurlik ook geredeneer kon word dat besnydenis en reinigingsbad algaande so saamgevoeg geraak het, dat hulle uiteindelik gesamentlik as verbondteken vir die proseliet gegeld het. Hoe aanloklik so 'n aanname ook al mag lyk, dit neem nie weg nie dat elkeen tog sy eie te onderskeie karakter gehad het, soos daar by Israel en die Jodedom onderskei moet word tussen besnydenis en rituele reiniging. Die 
reinigingsbad van die proseliet sou om hierdie rede kwalik in dieselfde $\sin$ as cie besnydenis as verbondsteken kon geld. "It is quite clear that circumcision was die decisive rite" (Pusey 1984: 143). Wat meer is, anders as by die Jood, is die proseliet nie besny of ritueel gereinig omdat hy deur geboorte aan die verbond deel gehad het nie, maar sodat hy daaraan deel kon kry.

Dit bring ons by die vraag of ons inderdaad van hierdie reinigingsbad as 'n sakrament of 'n doop kan praat. Dit lyk nie korrek nie, en wel in die lig van die feit dat dit 'n handeling was wat die proseliet self voltrek het en dat dit in werklikheid die eerste reinigingshandeling was van baie wat hy daarna in die Joodse gemeenskap sou uitvoer. Aan die ander kant kan 'n mens nie ontkom aan die gedagte dat hierdie bad tog beskou is as meer as slegs 'n eerste reinigingshandeling nie. Dit is daarom ook ' $n$ vraag of dit bloot as 'n rituele handeling beskou is en nie ook in 'n sekere sin as ' $n$ bad met inisiasie karakter nie. Geleerdes is nie eenstemmig oor die saak nie. Waarskynlik moet Pusey in 'n aansienlike mate gelyk gegee word wanneer sy sê: "It was more than the initial lustration designed to cleanse the convert from his pagan past and set him on the road that would contain many such lustrations. There was a 'once-for-allness' about this baptism, marking it off from normal repeatable lustrations" (1984: 143). Dieselfde standpunt word byvoorbeeld ook gehuldig deur Moore met die volgende stelling: "It is essentially an initiatory rite, with a forward and not a backward look" (1970:334).

Maar al sou dit waar wees dat hierdie bad in 'n sekere sin 'n inisiasie karakter gehad het, sou dit 'n oorspanning van die saak wees om dit'n sakrament of 'n doop te noem in die sin waarin dit normaalweg verstaan word.

Wat die verhouding besnydenis en reinigingsbad aan die een kant en verbond aan die ander kant betref, is daar natuurlik die belangrike aspek wat ons nie oor die hoof mag sien nie. Dit is die feit dat in die geval van'n gesin, beide ouers èn kinders die besnydenis en/of die reinigingsbad ondergaan het. In hierdie verband moet egter weer daarop gewys word dat in Joodse milieu dit eenvoudig vanselfsprekend was dat alle manlikes die besnydenis as verbondsteken moes ontvang en dat alle nie-Jode ritueel gereinig moes word vóór opname in die Joodse gemeenskap. 


\section{DIE REINIGINGSBAD BY DIE KOEMRAANGEMEENSKAP}

\subsection{Die Koemraangemeenskap as verbondsgemeenskap}

Dit is uit die geskrifte van hierdie gemeenskap meer as duidelik dat hy homself gesien het as 'n esoteriese verbondsgemeenskap. Terwyl die term $b^{e}$ rit op menige plekke in die Dooie See Rolle voorkom, is die hoofkonsentrasie daarvan te vind in die Gemeente- of Ordereël (I QS) in die Damaskusskrif (CD). Dit is binne hierdie bestek onmoontlik en vir ons doel onnodig om op al die fasette van die verbond by Koemraan in te gaan. Wat egter vir ons doel belangrik is, is die feit dat hierdie gemeenskap homself gesien het as die gemeenskap wat die eise wat God in sy verbond met Israel gestel het, nakom. Israel het ná die aartsvaders God se verbond verontagsaam deurdat hy ongehoorsaam was en nie die wet van Moses onderhou het nie. Dit geld veral vir dié in die land van Juda waarvan die lede van die Koemraangemeenskap hulle onttrek het. As gemeenskap sit hulle nie alleen die verbond met God voort nie, God het in werklikheid met hulle 'n nuwe verbond gesluit, "die nuwe verbond in die land van Damaskus" (CD VI: 19; VIII: $21 ; X X: 12)$. Hulle is dus nie alleen die ware verbondsgemeenskap nie, hulle is ook die nuwe verbondsgemeenskap. Hierdie nuwe verbond bevat ook nuwe openbaring (CD III: 14) en dit is eskatalogies gerig, dié wat hulle daaraan hou, is vir die ewige lewe bestem (CD III: 20).

Soos van 'n gemeenskap soos hierdie verwag kon word, is daar baie sterk klem gelê op die nakoming van die voorwaardes, vereistes en bepalings van die verbond. Van die lede van die gemeenskap word verwag om die verbond te hou (CD XIX: $1 ; X X: 17)$ en 'n eed af te lê om na die wet van Moses terug te keer (CD XV: 5, 8, 9, 12; QS V: 8). Om die verbond te hou, bestaan daarin dat volkome in die weë van God gewandel word (I QS ${ }^{b} 1: 2$ ). Maar byna nog sterker as wat daar opgeroep word tot nakoming van die voorskrifte van die verbond, word gewaarsku teen oortreding daarvan en die straf vir so 'n oortreding (CD I: 17, 18; XV: 2, 3; XIX: 13; I QS II: 15, 16). Hierteenoor is vergewing van sondes die beloning vir die nakoming van die voorskrifte van die verbond (I QS III: 7-12). Belydenis van sonde is daarom ook'n belangrike vereiste. So bely die lede van die gemeenskap dan ook: "Ons het goddeloos gehandel, ons en ons voorvaders, deurdat ons teen die bepalings van die verbond gehandel het" (CD XX: 28-29; kyk ook I QS II: 25-26). Bekering en belydenis van sonde neem so ' $n$ prominente plek in dat van die verbond gepraat kan word as die verbond van 
bekering ( $b^{e}{ }_{r i t} t^{e} s \bar{u} b \bar{a} h, \mathrm{CD}$ XIX: 16). Maar so seker is die gemeenskap daarvan dat God sy verbond as genadige God in stand hou, dat van hierdie verbond ook gepraat word as die verbond van barmhartigheid ( $b^{e}$ rīt hāsed, I QS I: 8).

\subsection{Die elemente van en handelinge by die toetredingsaksie}

Aangesien die verbond so ' $n$ allesoorheersende plek in die denke en lewe van die Koemraangemeenskap ingeneem het, het toetrede tot die gemeenskap toetrede tot die verbond beteken (CD VI: 19; I QS I: 16, 18, 20, 24; II: 10, 18; V: 8, 20 ens.) en andersom (I QS I: 16; vgl ook Kim 1981: 307). Die belangrikste elemente wat daar by toetrede gegeld het, is skuldbelydenis (I QS I: 24-26), belofte deur 'n eed om na die wet van Moses terug te keer en die onderneming om jou te distansieer van goddeloses en verbondsoortreders (I QS V: 8-10; VI: 15).

Uit die beskrywing wat gegee word van die prosedure wat gevolg moes word wanneer iemand hom by die gemeenskap wou aansluit, blyk dat die proses in hooftrekke soos volg verloop het (I QS VI: 13-23; vgl ook I QS 1:16-11:25): Die persoon wat van voorneme is om lid te word, moet eers ondervra word deur die pāqìd (een of ander leiersfiguur) oor sy insig/gesindheid (Verständnis, Lohse 1971: 23; understanding, Averbeck 1981: 279; insight, Thiering 1981: 616; prudence, Kim 1981: 293) en sy dade. Die pāqīd neem dan die eerste besluit oor die begin van die nuwe lid se opname. Is die pāqi $\bar{i}$ se besluit gunstig, dan laat hy die persoon 'n eed aflê om na die waarheid terug te keer en hom van die kwaad af te wend. Dan onderrig hy hom in al die verordeninge van die gemeenskap (mišp $e_{t \bar{e}}$ hayyähad.). Hierna bring die pāqūd hom voor die vergadering van die lede van die gemeenskap (härabbìm) en hulle oorweeg sy saak en besluit of daar met die opnameproses voortgegaan kan word. Is hulle besluit gunstig, word hy aan 'n proeftyd van een jaar onderwerp waartydens gelet word op sy gesindheid en sy dade. Gedurende hierdie tyd mag hy nog nie deel hê aan die volle gemeenskapslewe nie en sy besittings mag nie met dié van die gemeenskap gemeng word nie. $\mathrm{Na}$ afloop van hierdie proeftydperk besluit die gemeenskapslede weer oor hom, nadat hulle hulle vergewis het van sy gesindheid en sy onderhouding van die Torah. Is hulle besluit gunstig, word sy besittings oorhandig aan die $m^{e} b a q q e r$ (na alle waarskynlikheid dieselfde persoon as die pāqīd, vgl Thiering 1981: 616), maar dit word nog vir 'n jaar lank in bewaring gehou. Nou volg 'n verdere periode van een jaar waartydens hy nog nie deel mag hê aan 
die drank van die gemeenskap nie (vermoedelik die gemeenskaplike maaltyd, kyk Thiering 1981: $618 \mathrm{v}$ ), maar wel aan die reinheid van die gemeenskap. $\mathrm{Na}$ afloop van hierdie jaar word weer oor hom besluit en as die besluit gunstig is, word hy as volle lid opgeneem en sy besittings word die besittings van die gemeenskap.

In hierdie relaas oor die toetredingsaksie of opnameproses word daar geen uitdruklike melding van ' $n$ rituele wassing gemaak nie en indien dit wel tydens hierdie proses plaasgevind het, is dit moeilik om uit te maak wanneer dit gebeur het. Josefus (B J II, 8:7) is meer stellig oor die saak deurdat hy nie alleen so ' $n$ wassing vermeld nie, maar dit ook plaas by die begin van die voorlaaste proefjaar. Thiering (1981: 620) het op grond van sy ontleding van I QS VI: 13-23 tot dieselfde gevolgtrekking gekom, terwyl Kim (1981: $310 \mathrm{vv}$ ) van mening is dat dit by die begin van die laaste proefjaar geskied het. Hy maak sy gevolgtrekking op grond van sy afleiding dat die "reinheid van die menigte (baie)" (tāhorat hărabbīm) waarvan in I QS VI: 16-17 sprake is, verwys na hierdie reinigingsbad. Dat die rituele reiniging van die nuweling en die "reinheid van die menigte" in noue verband met mekaar gestaan het, is uit I QS V: 13 duidelik. Indien ons Kim se siening aanvaar dat die "water" en die "reinheid van die menigte" (in I QS V: 13) na dieselfde saak verwys, moet hy waarskynlik gelyk gegee word. Die saak bly nogtans onseker en laat hom nie maklik uitmaak nie. Dit is egter ook nie vir ons ondersoek van noemenswaardige belang nie.

Wat wel belangrik is, is die vraag of daar gedurende hierdie proses so 'n reiniging plaasgevind het, en nog belangriker is dit om te weet of hierdie wassing deur die Koemraangemeenskap as inisiasierite gesien is. Dat opname in die verbond en rituele reiniging saamgegaan het, lyk in die lig van die uitspraak in I QS V: 13 onontkenbaar. In hierdie teks word naamlik vanuit die konteks die uitspraak gemaak dat iemand wat hom nie tot die verbond bekeer nie, "nie die water mag betree nie". "The context clearly makes the two actions parallel; entry into the water belongs with entry into the community" (Thiering 1980: 270). Beteken dit egter dat hierdie wassing ' $n$ inisiasierite was of was dit maar slegs die eerste rituele reiniging waarvan daar nog baie vir hierdie lid in die Koemraangemeenskap sou volg? Soos ten opsigte van die proselietedoop is geleerdes ook nie hieroor eenstemmig nie. ' $n$ Aantal geleerdes soos byvoorbeeld Braun (1966: 6v) en Black (1961: 98) vind die gedagte van inisiasierite onaanvaarbaar, hoewel Black toegee dat Josefus se weergawe die indruk gee dat dit "a special form of lustration" was (1961: 96). Thiering sluit hom by hulle aan deur te verklaar: "The 
washing was not the real entry, but was associated with the entry. It was a secondary rite only, and able to be repeated as often as the flesh was defiled" (1980: 270). Thiering grond sy argument daarop dat die toetrede tot die gemeenskap sowel as herhaalde reiniging as lid van die gemeenskap volgens I QS III: 6-9 op tweërlei wyse geskied het, naamlik deur middel van 'n innerlike en 'n uiterlike reinigingsrite onderskeidelik. Die reiniging van die innerlike "real guilt" geskied deur die Heilige Gees, terwyl die uiterlike reiniging van die liggaam, wat slegs "secondarily impure" is, deur water geskied (1980: $267 \mathrm{vv}$; hierteen Averbeck 1981: 282).

Of 'n mens nou ook al Thiering se standpunt steun of nie, feit is dat die rituele wassing by die toetrede van 'n nuwe lid in die Koemraangemeenskap slegs maar één element was te midde van verskeie ander in die lang en moeisame inisiasieproses. Selfs al sou ons dus aanvaar dat hierdie (eerste) reinigingsbad ' $n$ besondere karakter gehad het en dáárom as inisiasierite beskou kan word, kan dit nie as enigste element of rite uitgesonder word nie. Die aanvanklike eed wat die nuweling afgelê het en sy eerste deelname aan die gemeenskaplike maaltyd, sou met net soveel reg as inisiasierites beskou kon word. Hierby moet daarop gewys word dat die rituele karakter van hierdie reinigingsbad sterk op die voorgrond gestaan het. Hiermee word natuurlik nie gesê dat dit geen verband gehad het met die bekering van die nuweling en sy voorneme om gehoorsaam te wees aan die wet van Moses nie. Die rituele aspek was egter die oorwegende (kyk bv Braun 1966: 7; Dinkler 1962: 628; anders Kuhn 1961: 748).

\subsection{Wie was betrokke?}

Hoewel daar in grafte in die omgewing van die Koemraanruïne ook aanduidings is dat vroue daar begrawe is, dui alles daarop dat die Koemraangemeenskap as sodanig net uit mans bestaan het. Die proses van opname van 'n nuwe lid veronderstel vanselfsprekend dat alleen volwassenes kon lid word van die verbondsgemeenskap. Die lede van die gemeenskap moes hoofsaaklik uit Jode bestaan het. Die hierbo genoemde voorskrif vir die opnameproses begin dan ook met die woorde: "Elkeen uit Israel wat hom gewillig betoon...". Dat daar egter ook proseliete in die gemeenskap aanwesig was, blyk duidelik uit CD XIV: 4,6. Hier word hulle wat woonplek en inskrywing in die gemeenskapsregister betref, in rangorde vierde geplaas na onderskeidelik die priesters, leviete en gewone Joodse lede. Hoe 'n groot persentasie hulle uitgemaak het, kan natuurlik nie meer bepaal word nie. Dat hulle vóór 
toetrede tot die gemeenskap ook besny sou moes word, kan as seker beskou word.

Die antwoord op die vraag na die verhouding reinigingsbad en verbond, hang natuurlik in 'n groot mate af van die vraag of hierdie reinigingsbad wel as ' $n$ inisiasierite beskou kan word. Hierbo by 2.2 is betoog dat dit nie aanneemlik blyk te wees nie. As element van die opnameproses het dit wel deel uitgemaak van die inisiasiegebeure en derhalwe van die toetrede tot die verbond. Dit was egter nie ' $n$ eenmalige gebeurtenis nie en kan nie as verbondsteken getipeer word nie. In watter mate die besnydenis hier nog as verbondsteken gesien is, is moeilik vasstelbaar. Feit is egter dat die Koemraangemeenskap 'n Joodse gemeenskap was en dat sy lede daarom almal besnedenes moes gewees het. $\mathrm{Al}$ is dit so dat die gemeenskap homself as gemeenskap van die nuwe verbond gesien het, was die nuwe verbond tot op groot hoogte die vernuwing van die ou verbond en 'n terugkeer tot die wet van Moses. Dit is egter meer duidelik dat lid-wees van die Joodse volk, met besnydenis en al, niemand outomaties aanspraak gegee het op lidmaatskap van die nuwe verbond of verbondgemeenskap van Koemraan nie. Daarom geld ook hier wat met betrekking tot die proselietedoop gesê is, naamlik dat die inisiasie nie plaasvind omdat die persoon kragtens geboorte deel van die verbondsvolk is nie, maar sodat hy deel van die nuwe verbondsvolk kan word. Hier is dus niks erfliks ter sprake nie en die toetrede is ' $n$ bewustelike keuse en selfstandige handeling van die nuweling wat hy op eie verantwoordelikheid onderneem.

\section{GEVOLGTREKKING}

Uit wat ons tot dusver uit die ondersoek na ons onderwerp te wete gekom het, kan ons nou samevattend deur middel van ' $n$ paar stellings die volgende gevolgtrekking maak:

- By beide die proselietedoop en Koemraan het dit uit die aard van die saak gegaan om opname in 'n nuwe verbondsgemeenskap en was die inisiasierite of -gebeure dus nie die beseëling of bevestiging van iets waarvan die nuweling deur geboorte reeds erflik deel was nie.

- In albei gevalle word daar sterk klem geplaas op die nakoming van gebooie en voorskrifte (by Koemraan ook nog voorafgaande skuldbelydenis en bekering), hoewel die verbond as genadegawe van God in die breëre konteks beslis gefigureer het.

- By Koemraan is opname in die verbondsgemeenskap voorafgegaan 
deur 'n sorgvuldige toetsing van die nuweling en 'n uitgebreide onderrig oor die verordeninge wat in die gemeenskap geld, terwyl in die geval van die proseliet, hy reeds as foboumenos vir geruime tyd met die meeste bepalings en voorskrifte van die Torah bekend moes gewees het.

- In die geval van die proselietedoop was dit volwassenes èn kinders wat betrokke was, terwyl dit by Koemraan slegs volwassenes (mans) was.

- In albei gevalle was die reinigingsbad, hoewel belangrik, slegs 'n onderdeel van die proses van opname.

- In albei gevalle was dit 'n selfbad en 'n volledige wassing.

- Daar is verskil onder geleerdes oor die vraag of hierdie bad gesien moet word as ' $n$ besondere (eenmalige) handeling wat te onderskei is van die gebruiklike rituele reinigingsgebruike en derhalwe as 'n inisiasierite beskou kan word.

- Al sou dit ook in ' $n$ sekere sin as 'n besondere, eenmalige handeling en daarom as 'n soort inisiasierite gesien moet word, (in die geval van die proselietedoop waarskynlik meer as by Koemraan) moet aangeneem word dat dit oorwegend as 'n rituele reiniging gesien is en nie as simboliese sondeafwassing nie. Hierdie reinigingshandeling het die nuweling in die situasie geplaas dat hy nie die lede van die gemeenskap sou verontreinig nie en sou kon deel hê aan die heilige (rein) dinge, soos onderskeidelik die offer by die tempel en die gemeenskaplike maaltyd by die Koemraangemeenskap. By Koemraan word daar wel die vereiste gestel dat iemand hom eers tot die verbond moet bekeer, alvorens hy die water kan betree (kyk weer I QS V:13), maar of ons op grond hiervan die reinigingsbad as simboliese sondeafwassing mag beskou, is te onseker.

- By beide die proselietedoop en Koemraan is die besnydenis klaarblyklik steeds gesien as dié teken van lidmaatskap van die verbondsvolk. By Koemraan het blote besny-wees en lid-wees van die Joodse volk jou egter nog geen aanspraak van die nuwe verbondsgemeenskap gegee nie. Jy kan alleen na aansienlike insette van jou kant, daarin opgeneem word.

- Die reinigingsbad moes in die lig van bogenoemde ' $n$ ander betekenis en funksie gehad het as om verbondsteken te wees.

- Hoewel die proselietedoop die waarskynlikste analogie vir die Christelike doop kon wees, is dit te bevraagteken of dit as 'n doop getipeer kan word en of die twee wesenlik enigsins vergelykbaar is.

- Vir sover die Christelike doop deur die vroeë kerk as 'n soort inisiasierite beskou is, het dit 'n antesedent by beide die proselietedoop 
en Koemraan, maar dan alleen wat die totale opnameproses betref en nie slegs die reinigingsbad nie.

- As naaste moontlike analogie vir die Christelike doop kan alleen die Johannesdoop wat 'n aansienlike ontwikkeling vanaf die proselietedoop en die Koemraanwassing verteenwoordig, kwalifiseer.

\section{Literatuurlys}

AVERBECK, RE 1981. The focus of baptism in the New Testament. Grace Theol Journ 2, 265-301.

BLACK, M 1961. The Scrolls and christian origins. London: Nelson.

BRAUN, H 1966. Qumran und das Neue Testament II. Tübingen: Mohr.

DAVIES, WD 1962. Paul and rabbinic Judaism. 2nd edition. London: SPCK.

DINKLER, E 1962. Taufe, in Werbeck, W (Hrsg) 1962. RGG VI. 3.Auflage, Tübingen: Mohr.

KIM, EW 1981. An eschatoligical examination of the new covenant based on the Dead Sea Scrolls. Michigan: University Microfilms International.

KUHN, KG 1961. Qumran, in Werbeck, W (Hrsg) 1961. RGG V. 3. Auglage, Tübingen: Mohr.

KUHN, KG s.a. Prosēlutos, in Friedrich, G (Hrsg) s.a. ThWNT VI. Stuttgart: Kohlhammer. LOHSE, E 1960, in Werbeck, W (Hrsg) 1960. RGG IV. 3. Auflage, Tübingen: Mohr.

LOHSE, E 1971. Texte aus Qumran. München: Kösel.

MOORE, GF 1970. Judaism I. Cambridge: Harvard UP.

OEPKE, A s.a. Baptō, in Kittel, G (Hrsg) s.a. ThWNT I. Stuttgart: Kohlhammer.

PUSEY, K 1984. Jewish proselyte baptism. Exp Times 95, 141-4.

SANDERS, EP 1977. Paul and Palestinian Judaism. London: SCM.

SCHÜRER, E 1979. The history of the Jewish people in the age of Jesus Christ (175 B.C.-A.D. 135) II. (Revised edition Vermes, G, F Millar \& M Black). Edinburgh: Clark.

STRACK, HL \& P BILLERBECK 1969. Kommentar zum Neuen Testament aus Talmud und Midrasch. 5. Auglage, München: Beck.

THIERING, BE 1980. Inner and outer cleansing at Qumran as a background to New Testament baptism. NTS 26, 266-77.

THIERING, BE 1981. Qumran initiation and New Testament baptism. NTS 27, 615-31. 